\title{
Knowledge, attitudes and practices regarding antimicrobial use and resistance among communities of Ilala, Kilosa and Kibaha districts of Tanzania
}

\author{
Calvin Sindato ${ }^{1,2^{*}}$ (0), Leonard E. G. Mboera ${ }^{2}$, Bugwesa Z. Katale ${ }^{2,3}$, Gasto Frumence ${ }^{2,4}$, Sharadhuli Kimera ${ }^{2,5}$, \\ Taane G. Clark ${ }^{6}$, Helena Legido-Quigley ${ }^{6}$, Stephen E. Mshana ${ }^{2,7}$, Mark M. Rweyemamu² and Mecky Matee ${ }^{2,4}$
}

\begin{abstract}
Background: Antimicrobial resistance (AMR) represents one of the biggest threats to health globally. This crosssectional study determined knowledge, attitudes and practices (KAP) regarding antimicrobial use (AMU) and AMR among communities of Ilala, Kilosa and Kibaha in Tanzania.

Method: A semi-structured questionnaire was used to collect socio-demographic and KAP data through face-toface interviews. Responses related to the triad of KAP were assigned scores that were aggregated for each participant. Linear regression analysis was conducted to determine predictors of KAP scores.

Results: The study enrolled 828 participants from the three districts. A total of 816 (98.6\%) were aware of antimicrobials, and $808(99 \%, n=816)$ reported to have used them. Antimicrobials were mainly used to treat cough $(68.0 \%)$, urinary tract infections (53.4\%), diarrhoea (48.5\%) and wounds (45.2\%). The most frequent sources of antimicrobials were health facility $(65.0 \%, n=820)$ and pharmacies/basic drug shops (53.7\%). The median AMU knowledge score was $5(I Q R=4,7)$ and that of AMR was $26(I Q R=23,29)$. The median AMU attitudes score was $32(I Q R: 29,35)$ and that of AMR was $19(\mathrm{IQR}=17,22)$. The median AMU practice score was $3(\mathrm{IQR}: 3,3)$. The KAP scores were significantly influenced by increased participant's age ( $\left.\beta_{\mathrm{adj}}=0.10 ; 95 \% \mathrm{Cl}: 0.05,0.15\right)$ and level of education, being lower among those with primary education ( $\beta_{\text {adj }}=5.32 ; 95 \% \mathrm{Cl}: 3.27,7.37$ ) and highest among those with college/university education $\left(\beta_{\text {adj }}=9.85 ; 95 \%\right.$ Cl: 6.04, 13.67).
\end{abstract}

Conclusion: The study documented a moderate level of KAP regarding AMU and AMR in the study districts. The participant's age and level of education were significantly associated with participant's KAP scores. The observed inadequate knowledge, inappropriate attitude, and practices of AMU and AMR should be considered as alarming problems that require immediate actions including policy formulation and planning of community-based mitigation measures.

Keywords: Antimicrobial, Use, Resistance, Community, Knowledge, Attitude, Practices, Tanzania

*Correspondence: csindato@gmail.com

2 SACIDS Foundation for One Health, Sokoine University of Agriculture, Morogoro, Tanzania

Full list of author information is available at the end of the article

\section{Introduction}

Antimicrobial resistance (AMR) has remained as one of the growing public health problem globally [1]. The misuse and abuse of antimicrobials in agriculture, veterinary, and human medicine have been described as major contributing factors for the emergence of AMR globally [2-4]. In clinical settings in Tanzania, the prevalence of original author(s) and the source, provide a link to the Creative Commons licence, and indicate if changes were made. The images or other third party material in this article are included in the article's Creative Commons licence, unless indicated otherwise in a credit line to the material. If material is not included in the article's Creative Commons licence and your intended use is not permitted by statutory regulation or exceeds the permitted use, you will need to obtain permission directly from the copyright holder. To view a copy of this licence, visit http://creativecommons.org/licenses/by/4.0/. The Creative Commons Public Domain Dedication waiver (http://creativeco mmons.org/publicdomain/zero/1.0/) applies to the data made available in this article, unless otherwise stated in a credit line to the data. 
multidrug-resistant bacteria ranges from $25 \%$ to $50 \%$ [5-7]. About two-thirds of isolates from wounds infections at Muhimbili National Referral Hospital were found to be resistant to at least three classes of antimicrobials [8]. Unchecked and uninformed antimicrobial use, including lack of knowledge of the course of antimicrobials, their side effects, standard acceptable dosage limits, and consequences of overdose, are the potential reasons for inappropriate or incorrect treatment or even misdiagnosis, potentially leading to AMR [9]. Limited community knowledge, poverty, unavailability of healthcare services have also been associated with inappropriate antimicrobial use (AMU) [10-12]. In low and middleincome countries $\left(\mathrm{LMIC}_{\mathrm{S}}\right.$ ), misuse of antimicrobials has been associated with their availability over the counter, without prescription and weak regulatory frameworks $[1,13-15]$. Retail pharmacies in $\mathrm{LMIC}_{\mathrm{S}}$ are preferred as the primary level of patient care intensifying self-medication practices $[16,17]$. Yet, the pharmacological quality of antimicrobials dispensed in these settings remains questionable [18-20]. It has been reported that one-third of the population from $\mathrm{LMIC}_{\mathrm{S}}$ has inadequate knowledge about antimicrobials and their roles [21].

In $\mathrm{LMIC}_{S}$, the $\mathrm{AMR}$ is compounded by: (i) lack of access to appropriate antimicrobial therapy [16, 22]; (ii) weak regulations in the dispensing and use of antimicrobials for humans [23]; (iii) weak surveillance of AMU and AMR levels [24]; (iv) lack of updated AMU and treatment guidelines [25]; (v) lack of continuing medical/veterinary education on AMU for prescribers [26]); (vi) a weak regulatory framework for AMU in animal production and aquaculture combined with a tendency for animal owners to stock antimicrobials in their houses and engaging unskilled people such as farmers/peasants in treating animals [27]; and (vii) high degree of antimicrobial abuse by livestock keepers through failure in observing the recommended therapeutic doses, use of wrong routes of administration, arbitrary drug combinations and nonobservance of withdrawing periods [28]. Other reasons include a lack of basic knowledge on the concept of antimicrobial resistance among livestock keepers [21] and unregulated disposal of waste as well as self-medication using antimicrobials [2]. AMR is being observed at the time when there has been a diminishing number of novel antimicrobials, risking the rise of untreatable infections and the inevitable loss of life [29] especially in resourcelimited countries with limited treatment options.

The magnitude and consequence of AMU and misuse are unknown in many parts of Tanzania. There is a need for evidence from well-designed studies on community AMU practices to facilitate the planning and implementation of specific strategies and interventions to prevent their irrational use and hence to reduce the spread of
AMR. This study was therefore carried out to determine the knowledge, attitudes, and practices regarding AMU and AMR among communities with different livelihoods in three districts of Tanzania.

\section{Materials and methods \\ Study areas}

This study was carried out in the Ilala, Kilosa, and Kibaha districts of Tanzania from January to February 2020. The districts were selected based on their demographic and ecological characteristics. Ilala district in the city of Dar es Salaam (with a highest human population density of 3,133 people per square kilometre), is characterised by urban ecosystems, occupied by multiple activities and diverse socio-ecological systems ranging from informal housing, transport infrastructure, large waste dumping sites, agriculture, industrial commercial activities, fishing and sand mining. The district is highly polluted by effluents from Msimbazi river tributaries originating from different sources, leakage of effluent from waste dumps, abattoirs and domestic wastewater from septic tanks and pit latrines that are used by about $85 \%$ of the Dar es Salaam city population. Kibaha is located in Pwani Region in eastern Tanzania (with a population density of 34 people per square kilometre) and is characterised by small-scale crop production, fish farming and large and small-scale poultry farming with frequent use of antimicrobials. Kilosa district is located in Morogoro region (with a population density of 31 people per square kilometres) in central Tanzania and is characterized by a large population of pastoralists keeping cattle, sheep and goats and known to practice self-treatment, with frequent $\mathrm{AMU}$.

\section{Study design}

This cross-sectional community-based study utilized a quantitative data collection method that was applied through a purposive and random selection process of study areas and participants. Wards were treated as the smallest spatial entities to which the targeted sample was drawn. Six wards were selected from each of the study districts using a probability proportional to human population size. Based on socio-cultural and economical values, homogeneity regarding AMU practices was assumed to exist within the members of the same household and heterogeneity was assumed between the members from different households within a ward. In this case, the number of households proportional to the targeted sample size for each ward was randomly selected from the sampling frame that was obtained from the ward office. One adult member from each of the selected household completed the face-to-face interview administered using 
semi-structured questionnaire installed in AfyaData, a digital disease surveillance app [30].

\section{Sample size}

The pattern of AMU, and hence the risk of the onset of AMR, was assumed to vary between the three study districts and the sample size for community members to be recruited into the study was computed independently for each district. The prevalence of inappropriate AMU was estimated from studies carried out in the settings similar to each of the study districts. The prevalence of inappropriate AMU was estimated at 71.5\% [31], 90\% [32], and $74 \%$ [33], for Ilala, Kibaha and Kilosa, respectively. Assuming the finite population and relative precision of $5 \%$ at a $95 \%$ confidence interval, the minimum sample size was estimated to be 314, 139 and 296 for Ilala, Kibaha and Kilosa, respectively. Assuming a 10\% dropout or refusal rate, the resulting minimum sample size for Ilala, Kibaha and Kilosa was 345, 153 and 326, respectively. The targeted sample size for each district was divided equally into six wards.

\section{Data collection}

Before the commencement of data collection exercise, twelve research assistants were trained on the study objectives, study protocol, sampling strategy, community engagement and ethical issues. They were provided with visual aids including pictures of antimicrobials to make interactions with study participants clear or easy to understand. A pre-tested questionnaire was used to collect all data through face-to-face interviews. The data collected included socio-demographic characteristics (age, sex, occupation, village, workplace, and residence), knowledge of antimicrobials (what are they and their roles, types of antimicrobials known and health conditions treatable with antimicrobials), practices of AMU (preferences, frequency of use, sources, ill-health conditions treated, adherence to the treatment regimen, self-medication practices). We also assessed awareness and knowledge of AMR. In addition to dichotomous responses to some questions, the five-point Likert scales ('strongly agree,' 'agree, 'uncertain', 'disagree' and 'strongly disagree') were used to determine the participants' knowledge and attitudes regarding antimicrobials, their uses as well as the burden, actions and roles to address AMR.

\section{Data management and analysis}

The data collected from households were submitted on daily basis to a server located at Sokoine University of Agriculture, Morogoro Tanzania. After data collection, it was exported from the server to Excel spreadsheet for coding before been imported to Stata version
13 (Stata Corp., College Station, TX, USA) for cleaning, descriptive and statistical analysis. Responses to the triad of knowledge, attitudes and practices (KAP domains) were assessed using a scoring scheme. For dichotomous responses, a right response was given one score, and zero to the wrong/unanswered option. Multiple responses to each of the correct options were given one score; otherwise, no score was given [34]. Responses to the five-point Likert scale were given scores that ranged from " 5 " for the most appropriate answer to " 1 " for the least appropriate answer and summed to form a discrete variable [35]. The AMU knowledge scores ranged from 0 to 13, the AMR knowledge scores from 0 to 40, the AMU attitude scores ranged from 0 to 40 , the AMR attitude scores from 0 to 25 and that of AMU practice from 0 to 7 points.

The median total score of responses to questions related to each of the three KAP domains was calculated together with its interquartile range (IQR) presented as the first and third quartiles. The strength of associations between socio-demographic variables and knowledge, attitudes and practices regarding AMU and AMR was measured using Chi-square tests. The Levene's test for variance indicated a statistically significant difference in the variance of some of the scores across sociodemographic variables. For this reason, a pairwise test using "rank-sum" test was used with caution to test the difference of the median scores. For interpretation of the analysis outputs from the scoring scheme, a score greater than $80 \%$ of the possible maximum scores was considered good, between $60 \%$ and $80 \%$ were considered moderate and less than $60 \%$ was considered poor [35].

The influence of socio-demographic factors on participants' knowledge, attitude and practice scores were analysed using both bivariate and multivariate linear regression models. The null hypothesis tested was that the predictor coefficients are 0 , and the alternate hypothesis was that the coefficients are non-zero. First, the association between socio-demographic variables (independent variables) and each of the three KAP domains was screened for statistical significance at a p-value of $\leq$ 0.20 in bivariate analysis. From the bivariate analysis, the statistically significant variables were included in a multivariate linear regression analysis based on a forward variable selection approach utilising the likelihood ratio statistic and a p-value $\leq 0.05$. The results of bivariate and multivariate analysis were reported as regression coefficient beta $(\beta)$ and adjusted coefficient beta $\left(\beta_{\text {adj }}\right)$, respectively together with their corresponding confidence intervals $(95 \% \mathrm{CI})$ at a $\mathrm{p}$-value of 0.05 . The variables included in the modelling process were limited to those that did not show significant collinearity using a diagnostic cut-off value for tolerance $>0.1$ and variance inflation factor $<10$ [36]. The Spearman rank-order correlation 
coefficient (rho) was run to assess the relationship and direction of the association between each pair of knowledge, attitudes and practices scores for participants.

\section{Results}

\section{Socio-demographic characteristics}

A total of 828 participants from Kilosa (360, 43.5\%), Ilala (312, 37.7\%) and Kibaha (156, 18.8\%) were involved in the study. Females accounted for about three-quarter (73.1\%) of participants. The overall median age of participants was 40 years (IQR: 30,52$)$. The median age of females and males was 38 (IQR: 29, 50) and 45 (IQR: 34,58 ), respectively. In all the study districts, almost two-thirds of the participants were married. Overall, over half (59.4\%) had attained primary school education; $18.4 \%$-secondary; and 4.4\%-college/university education. Agriculture (growing crops and raising livestock) and business, each accounted for over a third of the main sources of income to participants. While almost three-quarter $(73.7 \%)$ of participants from Ilala reported business as the main source of income, majority of those from Kilosa (57.2\%) and Kibaha (46.8) reported agriculture (Table 1).

\section{Awareness and knowledge of antimicrobial use and resistance}

Of the 828 participants, 816 (98.6\%) were aware of antimicrobials. The level of awareness was significantly higher for participants from Kibaha $(100 \%, n=156)$ and Ilala $(99.7 \%, n=312)$ than those from Kilosa (96.9\%, $n=360)(p=0.003)$. The level of awareness tended to increase slightly with an increased level of education. The majority $(95.3 \%)$ of those with no formal education $(n=148)$ reported lower level of awareness than those with primary $(99.0 \%, n=492)$, secondary $(100 \%, n=152)$ and college/university $(100 \%, n=36)$ level of education $(p=0.002)$. The higher level of awareness was recorded among participants whose main source of income was petty trading $(99.8 \%, n=449)$ and agriculture $(99.8 \%$, $n=283)$ than those who were employed $(92.7 \%, n=96)$ $(p<0.001)$. The level of awareness was similar between males and females and did not vary with age $(p>0.05)$. Out of 816 participants who reported on awareness of antimicrobials, the majority (97.6\%) associated AMU with the treatment of diseases. Other reported uses of antimicrobials included prevention of diseases (13.3\%), growth promotion $(0.9 \%)$ and feed additives for animal production $(0.6 \%)$. The types of antimicrobials that were known to participants included amoxicillin (66.0\%), tetracycline $(23.8 \%)$, metronidazole $(20.7 \%)$, ampicillin (14.9\%), ampiclox (7.5\%), ciprofloxacin (5.2\%), penicillin (4.2\%), erythromycin (3.6\%) and doxycycline (2.3\%).

Participants frequently mentioned coughing (68.0\%), urinary tract infections (53.4\%), diarrhoea (48.5\%) and
Table 1 Socio-demographic characteristics of participants from Ilala, Kilosa and Kibaha

\begin{tabular}{|c|c|c|c|}
\hline Variable & Ilala $(n=312)$ & Kilosa $(n=360)$ & Kibaha $(n=156)$ \\
\hline \multicolumn{4}{|l|}{$\operatorname{Sex}(\%)$} \\
\hline Female & $229(73.4)$ & $252(70.0)$ & $124(79.5)$ \\
\hline Male & $83(26.6)$ & $108(30.0)$ & $32(20.5)$ \\
\hline \multicolumn{4}{|l|}{ Age in years } \\
\hline Median (IQR) & $38(29,50)$ & $40(30,54)$ & $40(29,53.5)$ \\
\hline \multicolumn{4}{|l|}{ Marital status (\%) } \\
\hline Single & $58(18.6)$ & $43(11.9)$ & $16(10.3)$ \\
\hline $\begin{array}{l}\text { Married/cohab- } \\
\text { iting }\end{array}$ & $222(71.2)$ & $256(71.1)$ & $109(69.9)$ \\
\hline $\begin{array}{l}\text { Widower/ } \\
\text { widow }\end{array}$ & $18(5.8)$ & $40(11.1)$ & $21(13.5)$ \\
\hline $\begin{array}{l}\text { Divorced/sepa- } \\
\text { rated }\end{array}$ & $14(4.5)$ & $21(5.8)$ & $10(6.4)$ \\
\hline \multicolumn{4}{|c|}{ Formal educational level attained (\%) } \\
\hline $\begin{array}{l}\text { No formal } \\
\text { education }\end{array}$ & $13(4.2)$ & $107(29.7)$ & $28(18.0)$ \\
\hline Primary & $173(55.5)$ & $184(51.1)$ & $92(59.0)$ \\
\hline Secondary & $91(29.2)$ & $37(10.3)$ & $24(15.4)$ \\
\hline College & $27(8.7)$ & $3(0.8)$ & $1(0.6)$ \\
\hline University & $4(1.3)$ & $1(0.3)$ & $0(0.0)$ \\
\hline \multicolumn{4}{|c|}{ Main source of income } \\
\hline Agriculture & $4(1.3)$ & $206(57.2)$ & $73(46.8)$ \\
\hline Employment & $75(24.0)$ & $25(6.9)$ & $19(12.2)$ \\
\hline Petty trading & $233(74.7)$ & $129(35.8)$ & $64(41.0)$ \\
\hline
\end{tabular}

wounds (45.2\%) as the health conditions frequently treated by antimicrobials. A significantly higher proportion of participants from Kibaha than those from other study districts reported fever $(47.4 \%, p<0.001)$, body aches/pains $(46.2 \%, p=0.002)$, malaria $(46.2 \%$, $p<0.001)$ and tonsillitis $(26.3 \%)$ as the conditions treatable with antimicrobials. On the other hand, a significantly larger proportion of participants from Ilala $(46.6 \%, p<0.001)$ than those from other districts reported cold, flu and runny noses as the conditions treatable with antimicrobials (Fig. 1).

The overall median score of AMU knowledge in the three districts was $5(\mathrm{IQR}=4,7)$. A relatively higher value of median score of 6 (IQR: 4, 7) was observed for participants from Kibaha than from Kilosa (median $=5$, IQR: 4,7$)$ and Ilala (median=5; IQR: 4,7$)(p=0.0065)$. The median score of knowledge tended to increase with an increased level of education as demonstrated by higher value recoded in participants with college/ university level of education (median $=7$; IQR: 5,8 ) than those with secondary (median $=6$; IQR: 4,7 ), primary (median $=5$; IQR: 4,7$)$ and those with no formal education (median=4; IQR: 3,6$)(p=0.0001)$. Overall, $84.9 \%$ and $15.1 \%$ of participants $(n=816)$ had a 


\section{- Ilala $(n=311)$ Kilosa $(n=349) \quad$ Kibaha $(n=156)$}

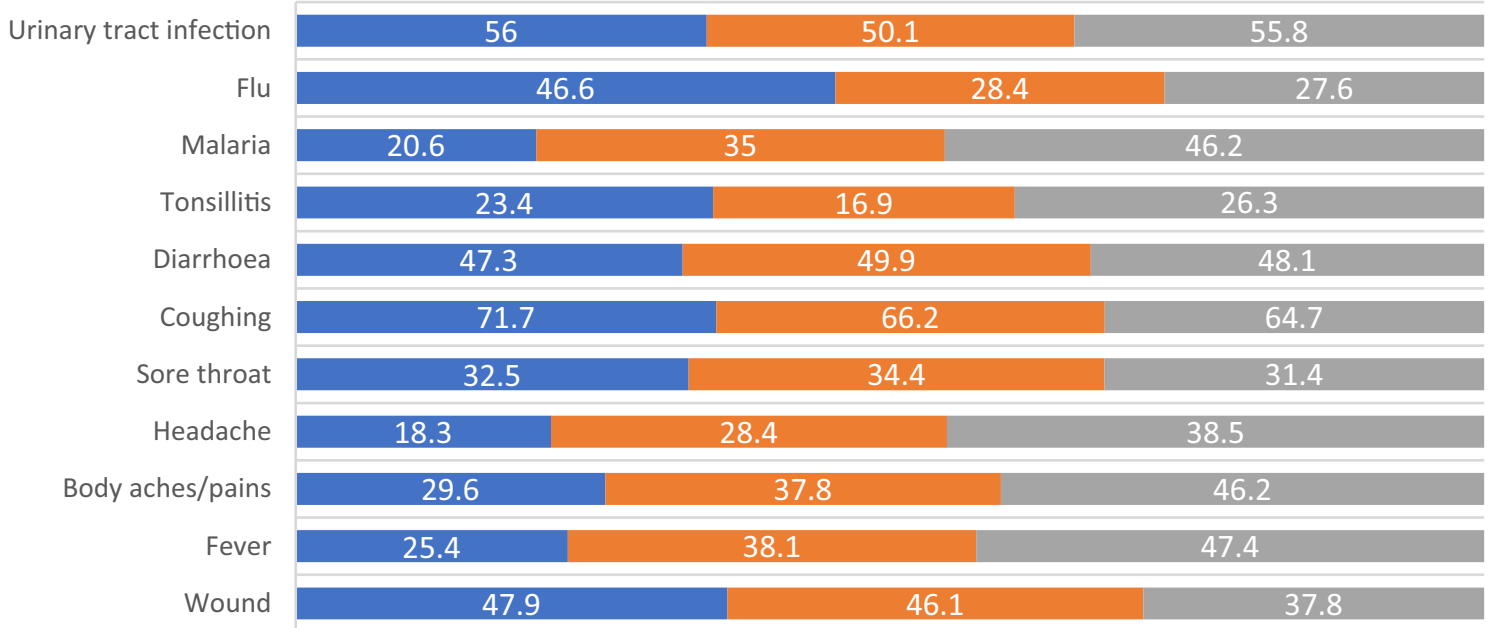

Fig. 1 Distribution of the proportion of participants on their awareness of disease conditions treatable with antimicrobials by district

poor and moderate levels of antimicrobial knowledge, respectively.

\section{Knowledge of antimicrobial resistance}

Over half of participants from Ilala (56.3\%) and less than half from Kilosa (40.4\%) and Kibaha (35.9\%) strongly agreed that AMR occurs when antimicrobials no longer able to treat infections $(p<0.001)$. This level of agreement was more evident among participants with secondary and college/university than those with a lower level of education ( $p=0.006)$. About half (52.0\%) of participants whose main source of income was from petty trading strongly agreed with the statement compared with those whose main source of income was agriculture (38.0\%) or employment $(37.1 \%)(p<0.001)$. Similarly, about half (51.8\%) of participants from Ilala and about one-third from Kilosa (35.2\%) and Kibaha (32.1\%) strongly agreed that many infections are becoming increasingly resistant to treatment by antimicrobials $(p<0.001)$. This level of agreement was observed more frequently among participants with secondary and college/university than those with lower levels of education $(p<0.001)$. Likewise, a relatively larger proportion $(46.7 \%)$ of participants whose main source of income was from petty trading strongly agreed with the statement than those who were employed $(34.8 \%) \quad(p<0.001)$ and those whose main source of income was from agriculture $(33.7 \%)(p<0.001)$.

In Ilala, over half (54.7\%) of participants strongly agreed that if the disease-causing germs are resistant to antimicrobials, it can be very difficult or impossible to treat the infection they cause. About one-third of participants from Kilosa (36.1\%) and Kibaha (34.0\%) expressed a similar level of agreement $(p<0.001)$. Males were more likely to strongly agree with the statement than females $(p=0.001)$. A similar pattern of the agreement was observed among participants aged $>33$ years old than among the younger ones $(p=0.026)$. Over twothirds $(69.4 \%)$ of participants with college/university level of education compared with those with secondary $(45.4 \%)$, primary $(43.5 \%)$ levels and those with no formal education $(30.5 \%)(p<0.001)$ strongly agreed that it is difficult to treat diseases caused by resistant pathogens. There was some statistical evidence to suggest that being from a petty trading category of occupation (47.8\%) was more likely associated with a tendency to strongly agree with the statement compared with being from employment $(38.2 \%)$ or agriculture $(36.2 \%)(p=0.013)$ category.

Over half $(55.6 \%)$ of participants from Ilala and less than half from Kibaha (46.2\%) and Kilosa (34.1\%) strongly agreed that AMR is mainly a problem for people who take antimicrobials frequently $(p<0.001)$. Over half $(58.3 \%)$ of participants with college/university level of education and less than half of those with lower levels of education expressed the same agreement $(p=0.001)$. About half $(50.9 \%)$ of participants from petty trading category and just over one-third of those who were employed (38.2\%) and those working in agriculture (36.6\%) expressed the same agreement. Only about onethird of participants from Kilosa (36.1\%), Ilala (34.7\%) and Kibaha (34.0\%) strongly agreed that disease-causing germs that are resistant to antimicrobials can be spread from person to person $(p=0.002)$. 
The overall median score of AMR knowledge in the three districts was $26(\mathrm{IQR}=23-29)$ but differed significantly between the sociodemographic variables. Participants from Ilala demonstrated a higher value (median=27; IQR: 23, 21) than those from Kibaha (median=26; IQR: 23, 29) and Kilosa (median=25; IQR: $22,29)(p=0.0003)$. The median score of knowledge on AMR increased with an increase in the level of education. A higher value was recorded in participants with college/university level of education (median $=28.5$; IQR: 26,31 ) than those with secondary (median=27; IQR: 23, $30)$, primary (median $=26$; IQR: 23,29$)$ or those without formal education (median=25; IQR: 22,28$)(p=0.0001)$. Participants whose major source of income was from petty trading had a higher median score of 27 (IQR: 23-30) than those who were employed (median $=25$, IQR: $22,29)$ and agriculture keeping (median $=25$, IQR: 22 , 29) $(p=0.0008)$. Males had significantly higher scores (median=27; IQR: 24, 31) than females (median $=26$, IQR: 23,29$)(p=0.0022)$. About two-thirds $(62.5 \%$; $n=816)$ of the participants had moderate knowledge of AMR, 29.5\% had poor knowledge and $8.0 \%$ had good knowledge.

\section{Attitudes on the appropriate use of antimicrobials}

Participants were presented with different statements related to the use of antimicrobials and asked on how much they would agree or disagree with them. More positive views largely accorded with the strongly agree category, as did the less positive with the disagree category. A significant difference was observed regarding attitudes. A larger proportion of participants from Kilosa (84.5\%), Ilala (83.6\%) and Kibaha (73.7\%) strongly agreed that people should use antimicrobials only when they are prescribed by the health care professionals $(p=0.002)$. Washing hands was considered one of the measures to prevent the spread of disease-causing germs and thus reduce AMU. When asked about this relationship, the largest proportion of participants who strongly agreed that people should wash their hands regularly were from Ilala (93.9\%) followed by Kibaha $(85.1 \%)$ and Kilosa $(85.1 \%)(p<0.001)$. On the other hand, more positive views that largely accorded with strongly agree category concerning health care professionals only prescribing antimicrobials when they are needed, were recorded in Ilala $(87.5 \%)$ followed by Kilosa $(73.1 \%)$ and Kibaha $(62.2 \%)(p<0.001)$. On the contrary, rather few views that accorded with the strongly agree category regarding people not keeping antimicrobials and use them for other illnesses, was recorded in Ilala (58.5\%), followed by Kibaha $(44.2 \%)$ and Kilosa $(43.0 \%)(p<0.001)$.

The overall median score of attitudes regarding appropriate AMU in the study districts was 32 (IQR: 29,
35). The attitude varied significantly between the districts, with higher values demonstrated by participants from Ilala (median=33; IQR: 30, 35) followed by Kilosa (median=32; IQR: 29, 35) and Kibaha (median=30; IQR: $27,33)(p=0.0001)$. Participants with college/university (median=33; IQR: 30,35 ) and primary (median=33; IQR: 29, 35) levels of education expressed better attitude than those with secondary (median=32; IQR: 29, 35) and those without formal education (median $=31$; IQR: 28 , 34) $(p=0.0007)$. Over two-third $(69.9 \%, n=816)$ of participants demonstrated a moderate attitude on the appropriate use of antimicrobials, $22.4 \%$ good attitude and $7.7 \%$ poor attitude.

\section{Attitudes on the burden of AMR}

About half of participants from Ilala (54.0\%), Kibaha (51.3\%) and less than half from Kilosa (41.2\%) strongly agreed that AMR is one of the biggest problems the world is facing currently $(p<0.001)$. Furthermore, almost two-thirds (64.1\%) of participants from Kibaha strongly agreed that Tanzania is among the countries facing the challenges related to AMR. On the contrary, less than half of the participants from Ilala (43.7\%) and Kilosa (38.4\%) had expressed a similar level of agreement $(p<0.001)$. The pattern of agreement with the statement tended to vary with the level of education as it was observed in over three-quarter $(86.1 \%)$ of participants with college/university level of education compared with those with secondary $(59.9 \%)$, primary $(55.7 \%)$ or with no formal education $(44.0 \%)(p=0.004)$. A relatively larger proportion $(60.0 \%)$ of participants from the petty trading category of occupation expressed the same agreement compared with those from agriculture (50.9\%) or employment (49.4\%) categories $(p=0.030)$.

About three-quarters of participants from Ilala (70.1\%) and a half from Kilosa (55.6\%) and Kibaha (53.9\%) strongly agreed that medical experts could resolve the problem of AMR before it becomes too serious $(p=0.001)$. While a greater proportion of participants from Ilala (71.4\%) and Kilosa (61.3\%) strongly agreed that everyone needs to use antimicrobials responsibly, those from Kibaha (44.2\%) were less likely to have a similar opinion $(p<0.001)$. Approximately, one third of participants from Kibaha (30.7\%), Kilosa (33.9\%) and Ilala (37.6\%) were of the opinion that they could at least do something to stop AMR $(p<0.001)$. While over half (56.0\%) of participants from Ilala were strongly worried about the impact that AMR will have on their health and that of their families, those from Kibaha (41.7\%) and Kilosa (39.5\%) were less likely to have same opinion $(p<0.001)$. Similarly, while over half $(57.6 \%)$ of participants from Ilala strongly agreed that they were not at risk of getting AMR infections, as long as they take 
antimicrobials correctly, fewer participants from Kilosa (45.0\%) and Kibaha (36.5\%) were likely to express a similar opinion $(p<0.001)$. Majority of participants from Ilala (81.7\%), and about two-third from Kilosa (67.6\%) and Kibaha (65.4\%) strongly disagreed with the statement that it is appropriate to use antimicrobials that were given to a friend or family member, as long as they were used to treat the same illness $(p<0.001)$. About half $(52.1 \%)$ of participants from Ilala, strongly disagreed with the statement that it is appropriate to buy the same antimicrobials, or request these from a doctor, if you are sick and they have helped you get better when you had the same symptoms before. However, relatively low proportions of participants from Kilosa (44.1\%) and Kibaha (43.0\%) were likely to express the same opinion $(p<0.001)$.

The overall median score of attitude regarding the burden of AMR and individual roles to address the problem was $19(\mathrm{IQR}=17,22)$. The distribution of the median scores differed significantly between the sociodemographic variables. Participants from Ilala demonstrated higher values (median=20, IQR: 17, 23) than those from Kilosa (median=19 (IQR: 16, 21) and Kibaha (median=18.5 (IQR: 16, 21) $(p=0.0018)$. The median score tended to increase with an increased level of education. Higher values were recorded in participants with college/university level of education (median $=20.5$; IQR: $19,23)$ than those with secondary (median=20; IQR: $17,22)$, primary (median=19; IQR: 17,22$)$ and no formal education (median=18; IQR: 16-20) $(p=0.0001)$. Participants whose major income was from agriculture (median=19; IQR: 16, 21) and petty trading (median=19;
IQR: 17, 22) had higher median scores than those whose major source of income was from employment (median $=17$, IQR: 15,21$)$ category $(p=0.0001)$. About half $(52.7 \%, n=816)$ of participants expressed moderate attitude regarding the burden of AMR and individual role to addressing the problem, over one-third (37.5\%) and $9.8 \%$ showed good and poor attitudes, respectively.

\section{Practices on use of antimicrobials}

Overall, almost all $(99.0 \%, n=816)$ participants who reported awareness on antimicrobials, affirmed to have ever used antimicrobials in their lifetime. They represented all participants from Kilosa and Kibaha, and 97.4\% of participants from Ilala $(p=0.001)$. Of the 808 participants who reported to have ever used antimicrobials, 718 (88.9\%) could recall the last time they had used antimicrobials. Specific periods of the history of AMU was organized into five categories, which were the past 7, 30, 180,365 and $>365$ days. When participants were asked to recall the last time they took antimicrobials, a significant difference was observed between the districts and sex $(p<0.05)$. Overall, the recent AMU was frequently reported among participants in Kilosa and Kibaha than Ilala. Almost two-thirds (61.5\%) of participants who reported to have ever used antimicrobials during the past 7 days $(n=179)$, were from Kilosa (Fig. 2). Throughout the recall periods, females were consistently on the higher frequency of AMU than males $(p=0.001)$ (Fig. 3). Besides the observed association between age and preference to antimicrobials, the actual AMU tended to be homogenously distributed across age groups $(p>0.05)$. A

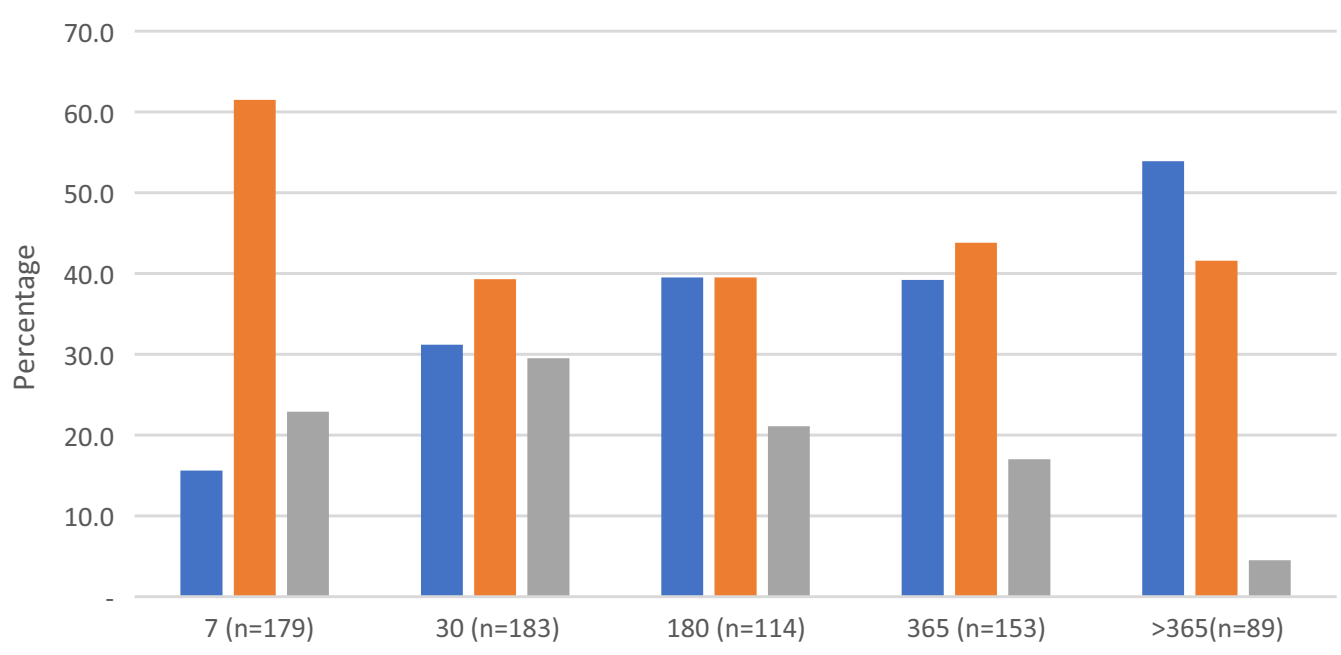

Number of days since antimicrobial was used for the last time

- Ilala Kilosa Kibaha

Fig. 2 Percentage distribution of participants' history of antimicrobials use by district 


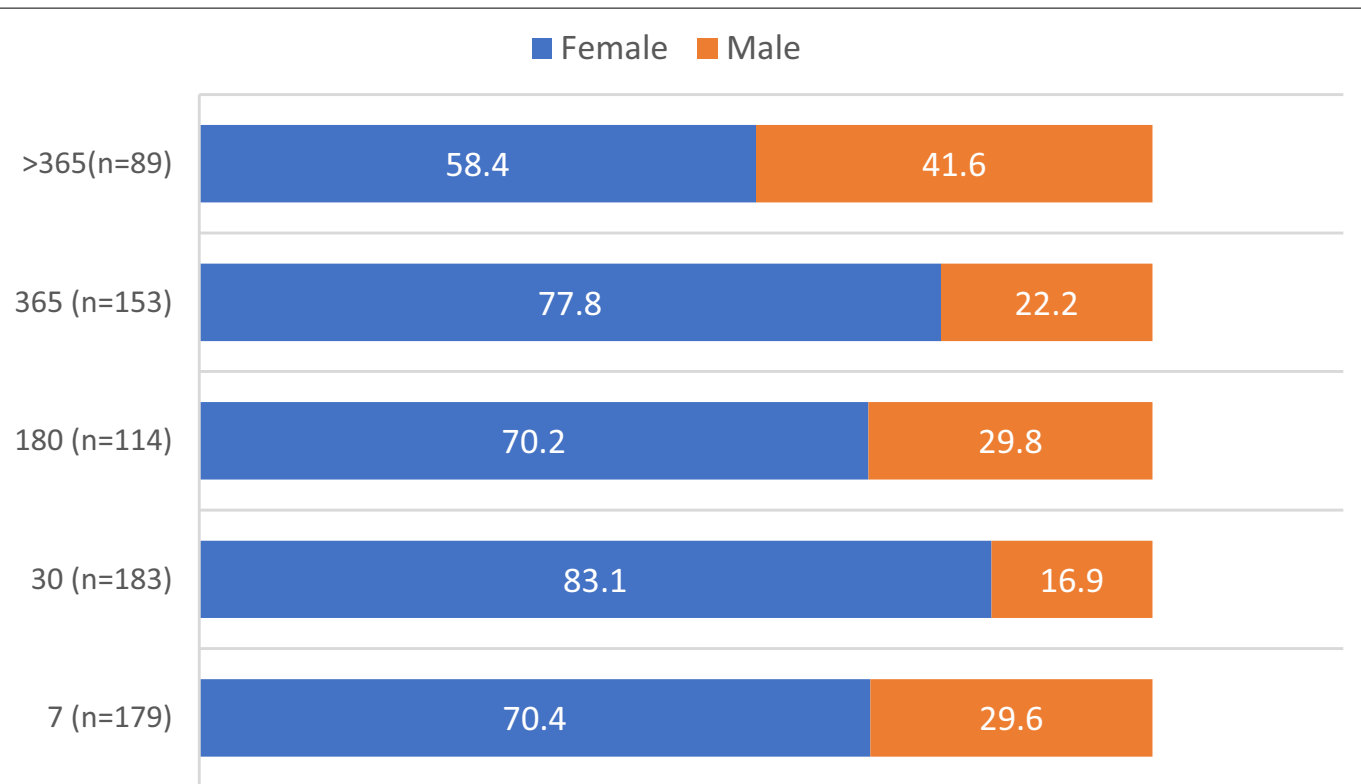

Fig. 3 Percentage distribution of participants' history of antimicrobial use by sex

similar pattern was observed for the association between the AMU and level of education, marital status or occupation $(p>0.05)$.

The overall median score of appropriate AMU was 3 (IQR: 3, 3). All three districts had the same median value. Participants from Kibaha and Kilosa had the same IQR $(3,3)$ while those from Ilala had IQR of 3, $4(p=0.0086)$. Similarly, the same median of 3 was observed across different levels of education and type of occupation, with slight differences in the IQRs. Participants with college/ university and secondary level of education had the same $\operatorname{IQR}(3,4)$ while those with primary $(3,3)$ and with no formal education $(2,3)$ had slightly less $(p=0.0086)$. Those whose main source of income was agriculture and petty trading had relatively higher IQR $(3,3)$ than those from employment category $(2,3)(p=0.0253)$. The results showed that almost all $(97.3 \%, n=816)$ had a poor practice of AMU, 2.8\% had moderate practice and $0.1 \%$ had a good practice.

\section{Preference for antimicrobials}

Amoxicillin was the most frequently preferred antimicrobial in all the three districts (Kibaha $=75.0 \%$; Ilala $=68.3 \%$; Kilosa $=60 \%)(p=0.002)$. A significantly larger proportion of participants from Kibaha had more preference for metronidazole (39.7\%) than those from Kilosa (19.2\%) and Ilala $(12.8 \%)(p<0.001)$. A higher proportion of participants from Kilosa (26.9\%) and Ilala (23.7\%) preferred tetracycline than those from Kibaha $(19.7 \%)(p=0.004)$. A significantly larger proportion of participants from Ilala (24.0\%) reported a preference for ampicillin than those from Kibaha $(9.6 \%)$ and Kilosa $(9.2 \%)(p<0.001)$. Only a few $(<10 \%)$ participants from Ilala, Kilosa and Kibaha had a preference to ciprofloxacin, erythromycin, penicillin or ampicillin/cloxacillin (Fig. 4).

Almost three-quarter of females $(71.9 \%, n=605)$ had preference to amoxicillin compared to males (49.8\%, $n=223)(p=0.001)$. A significant variation was observed on females' than males' preference to amoxicillin in Ilala and Kilosa $(p<0.001)$. Sex was not significantly associated with preference to this antimicrobial among respondents in Kibaha. Relatively larger proportion of participants aged 18-33 years old $(74.4 \%, n=282)$ and $34-47$ years old $(66.6 \%, n=275)$ had preference to amoxicillin than those aged $48-95$ years old $(56.6 \%, n=272)(p<0.01)$. When the analysis was controlled by the district, a similar pattern of significant variation in the association between age categories and preference to amoxicillin was maintained among participants from Ilala $(p=0.005)$ and Kibaha $(p=0.001)$ with insufficient evidence of statistical difference among participants from Kilosa $(p>0.05)$.

\section{Sources and factors influencing the choice of antimicrobials}

Overall, the most frequent sources of antimicrobials were health facility $(65.0 \%, n=820)$ and pharmacies/basic drug shops (53.7\%) (Fig. 5). A relatively higher proportion of participants from Kibaha $(62.8 \%, n=156)$ were more likely to obtain antimicrobials from pharmacies/ basic drug shops than those from Ilala $(53.3 \%, n=285)$ and Kilosa $(50.1 \%, n=379)(p=0.028)$. 


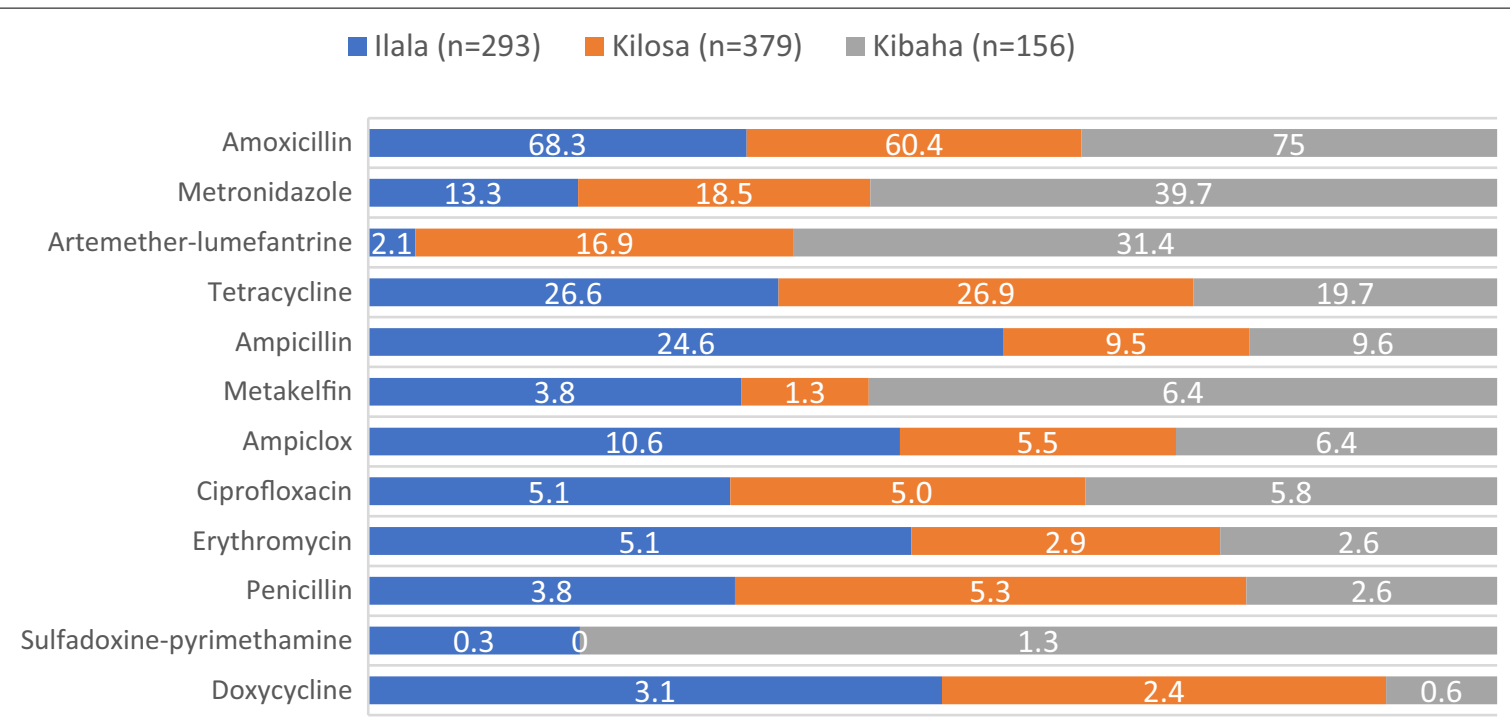

Fig. 4 Distribution of the proportion of participants on their antimicrobial preferences by district

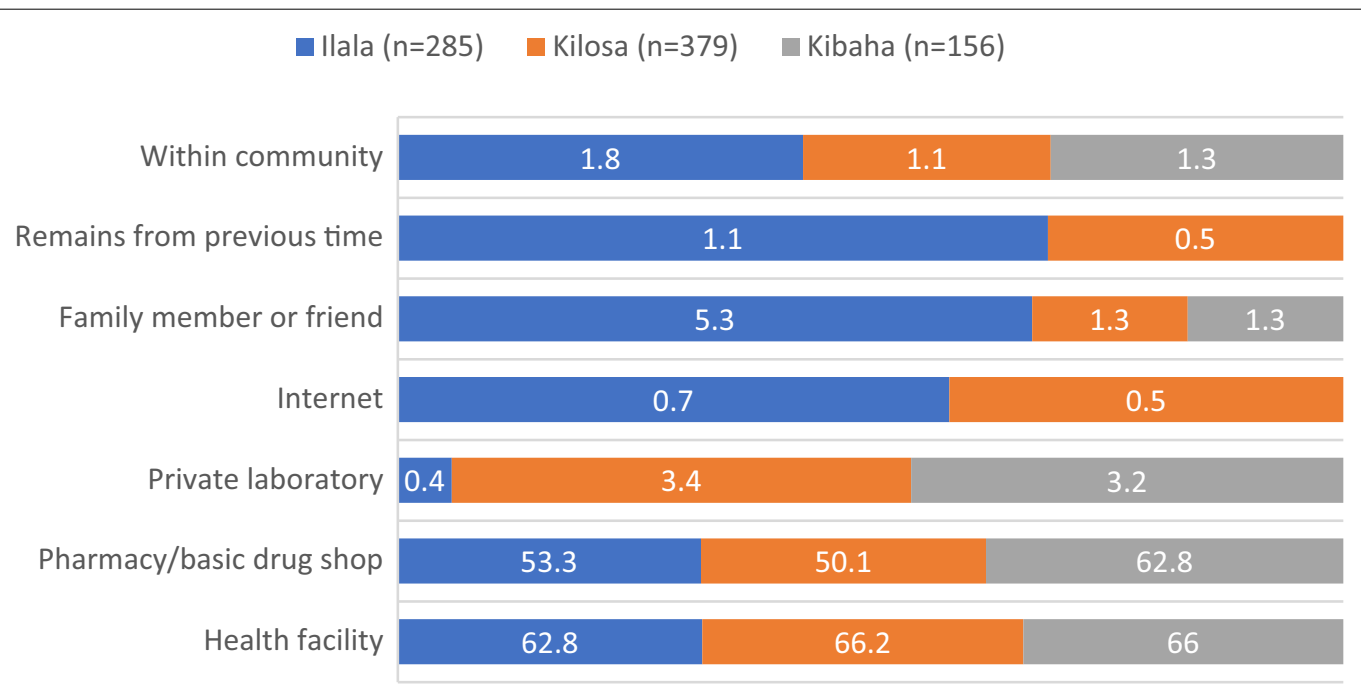

Fig. 5 Sources of antimicrobials frequently reported by participants by district

Overall, two-thirds $(65.5 \%, n=542)$ of participants reported that their choice of antimicrobial was influenced by advice from health care providers. Nearly a quarter (23.3\%) of participants had their choice influenced by advice from pharmacists, and this varied significantly between the districts. A relatively larger proportion of individuals from Kibaha $(37.8 \%, n=156)$ were more likely to rely on pharmacist's advice than those from Kilosa $(20.1 \%, n=379)$ or Ilala $(19.8 \%, n=293)(p<0.001)$. Less than a quarter $(17.4 \%)$ of all participants had their choice of antimicrobials influenced by experience from the previous episode. A relatively larger proportion of individuals from Ilala (24.2\%) had their choice driven by experience from the previous episode followed by those from Kilosa $(14.8 \%)$ and Kibaha $(10.9 \%)(p<0.001)$.

Although only $3.0 \%$ of individuals were likely to choose antimicrobials based on availability in the general public markets, there was statistical evidence to suggest that the practise was more frequent among participants from Kibaha $(8.3 \%)$ than those from Kilosa (2.6\%) or Ilala $(0.7 \%)(p<0.001)$. There was weak statistical evidence to suggest that individuals from Kilosa (15.6\%) and Ilala (11.6\%) were more likely to seek advice from their peers regarding the type of antimicrobial to use than those 
from Kibaha $(7.1 \%)(p=0.022)$. Availability of antimicrobials and individuals' affordability appeared to be the weak drivers for antimicrobial choice (Fig. 6). Individuals aged $48-95$ years old $(72.1 \%, n=272)$ were more likely to seek advice on antimicrobial to use from health care providers than their younger counterparts $(p=0.017)$. Individuals who were not married and those who had separated were less likely to seek advice from health care worker regarding the type of antimicrobials to use $(p=0.038)$.

\section{Adherence to the treatment regimen}

Overall, more than three-quarters $(80 \%, n=808)$ of individuals who reported to have ever used antimicrobials, were likely to complete a full course of treatment. Less than a quarter $(19.4 \%)$ reported that they would not complete the treatment regimen when they feel better after a three-day treatment. A relatively higher proportion of individuals from Ilala $(19.5 \%, n=312)$ were more likely to keep the leftover antimicrobials for future use compared with those from Kibaha $(15.4 \%, n=156)$ and Kilosa $(11.1 \%, n=360)(p=0.01)$. Likewise, a relatively higher proportion of individuals from Ilala (18.6\%) were more likely to dispose the leftover medicines compared with those from Kibaha (6.4\%) and Kilosa (3.9\%). Socio-demographic factors were found to have no significant influence on adherence to the treatment regimen $(p>0.05)$.

\section{Antimicrobial prescription and self-medication practices}

Overall, about three-quarter $(76.4 \%, n=808)$ of participants reported that it was a common practice to use antimicrobials with a prescription from the health care worker or pharmacist. When they were asked about the practice during the most recent time they had used antimicrobials; overall, $74.4 \%$ of reported to have used antimicrobials with a prescription. The most frequent reasons for self-medication practices were knowledge of the disease/syndrome affecting an individual (56.0\%), individual not been able to wait until she/he is served at a healthcare facility (25.9\%), affordability to seek medical care $(23.8 \%)$, suffering from dangerous signs $(21.8 \%)$ and distance to the healthcare facility (16.6\%) (Fig. 7). The knowledge of the disease condition affecting an individual varied between the districts with significantly greatest proportion been recorded from Ilala $(68.8 \%, n=80)$ followed by Kilosa $(53.3 \%, n=77)$ and Kibaha $(33.3 \%, n=36)(p<0.001)$. Likewise, individuals from Kibaha were more likely to express not been able to wait to visit a healthcare facility (44.4\%) than those from Kilosa $(22.1 \%)$ or Ilala $(21.3 \%)(p=0.019)$.

Out of 205 participants who reported to have practised self-medication, 193 (94.1\%) could recall the health conditions they were suffering from. The overall frequency of self-medication by a disease condition in the decreasing order were coughing $(43.0 \%)$, urinary tract infection (24.4\%), diarrhoea (22.3\%), wound (15.5\%), headache (15.5\%), fever (15.0\%), aches/pains $(13.5 \%)$, sore throats $(11.4 \%)$, malaria $(11.4 \%)$, colds, flu and runny noses (11.4\%) and tonsillitis (7.3\%). The largest proportion of individuals who had practised self-medication based on these conditions was consistently observed in Kibaha. However, coughing that was most frequently reported condition in Ilala, and colds, flu and runny noses, malaria and fever that were mainly reported by participants from Kilosa (Fig. 8).

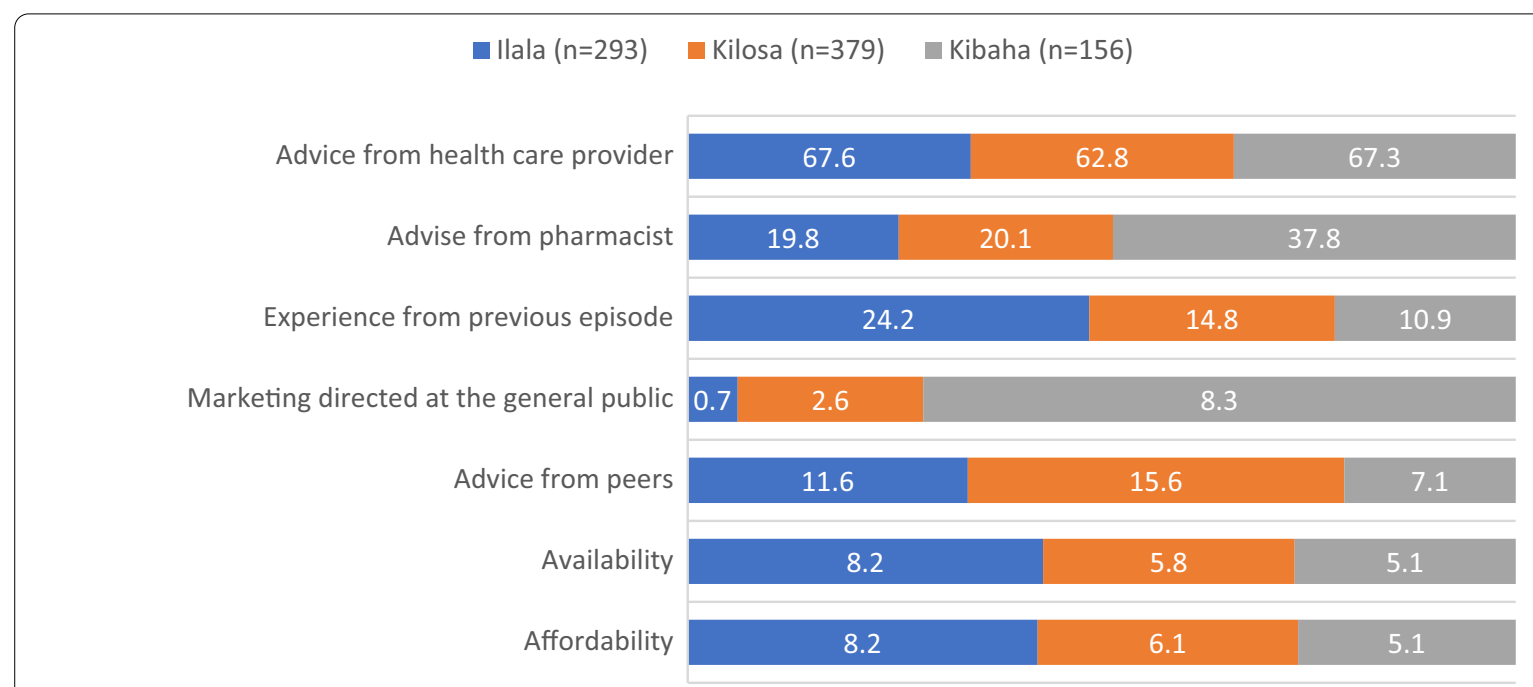

Fig. 6 The proportion of respondents as regards to factors influencing the choice of antimicrobials in by the district 
Knowledge of disease/syndrome affecting me

Affordability to seek medical care at health facility

Long distance to health facility

Could not wait to visit health facility

Had dangerous signs

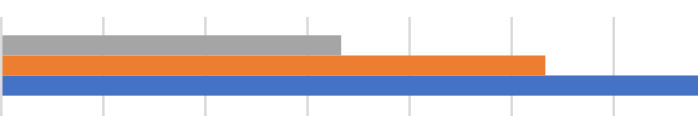

\section{.}

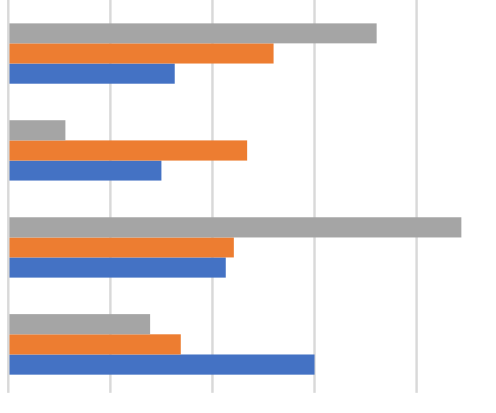

$\begin{array}{lllll}0 & 10 & 20 & 30 & 40\end{array}$

- Kibaha $(\mathrm{n}=36) \square$ Kilosa $(\mathrm{n}=77)$ ॥lala $(\mathrm{n}=80)$

Fig. 7 Reasons for self-medication by district

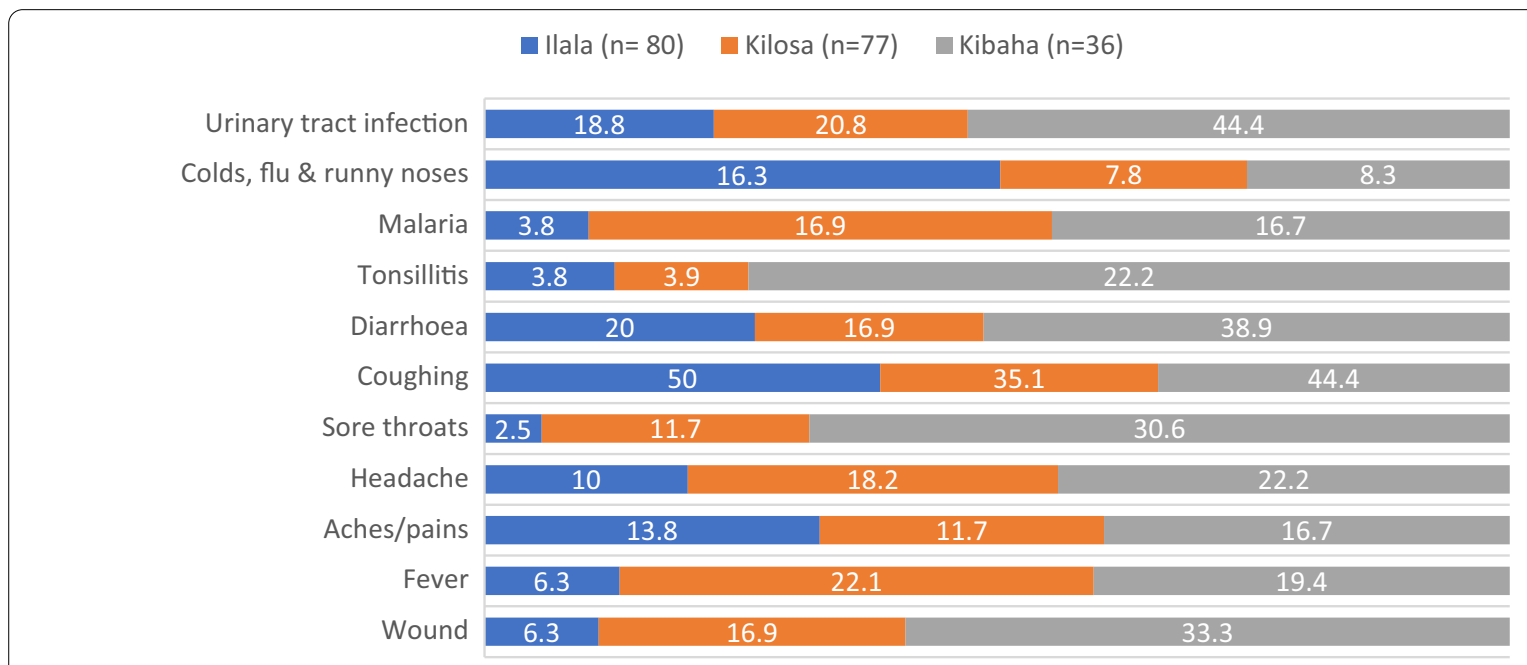

Fig. 8 Distribution of the proportion of disease conditions treated in humans by self-medication by district

Following self-medication, almost two-thirds (64.3\%) of participants reported having recovered from illness. However, about one-third (31.6\%) reported some improvement while $3.6 \%$ reported no change and $0.5 \%$ had their situation worsened. In the absence of favourable outcome following self-medication, $9.8 \%$ of participants $(n=193)$ took no action while $90.2 \%$ took some actions, which included $(n=174)$ seeking care from a healthcare facility $(16.1 \%)$, repeating self-medication (12, 6\%), visiting traditional healer (3.5 \%) and/or seeking care from spiritual healers $(0.6 \%)$. There was insufficient statistical evidence for sociodemographic factors to influence these practices $(p>0.05)$.

\section{Association between sociodemographic variables and knowledge, attitude and practices}

The results of bivariate linear regressions analysis showed that compared with participants from Kibaha, the scores of knowledge of antimicrobials were significantly lower by 0.49 and 0.45 among participants from Kilosa and Ilala, respectively. The antimicrobial knowledge scores tended to increase with an increased level of education. Participants with college/university $(\beta=1.93 ; 95 \%$ CI: $1.21,2.65)$, secondary ( $\beta=0.99$; $95 \% \mathrm{CI}: 0.54,1.44)$ and primary ( $\beta=0.72$; $95 \%$ CI: $0.35,1.09)$ education had significantly higher level than those with no formal education. For each unit increase of age, there was an increase 
of 0.03 (95\% CI: 0.01, 0.05) of AMR knowledge scores. High AMR knowledge scores were significantly associated with being a male $(\beta=1.16$; $95 \%$ CI: $0.41,1.90)$, having college/university education $(\beta=3.69 ; 95 \% \mathrm{CI}: 1.94$, $5.45)$, secondary education ( $\beta=3.69 ; 95 \% \mathrm{CI}: 1.94,5.45)$ and petty trading as the main source of income $(\beta=1.17$; $95 \%$ CI: $0.45,1.88)$. Compared with those from Kibaha, participants residing from Ilala $(\beta=1.89$; $95 \% \mathrm{CI}: 1.06$, $2.72)$ and Kilosa $(\beta=1.51 ; 95 \%$ CI: $0.70,2.33)$ had significantly higher scores of AMU attitude. High scores of AMU attitude were significantly associated with college/ university $(\beta=2.09 ; 95 \%$ CI: $0.50,3.68)$ and primary ( $\beta=1.63 ; 95 \%$ CI: $0.82,2.44)$ level of education.

A statistically significant association between AMR attitude scores and area of participant's residence was recorded in Ilala ( $\beta=1.01 ; 95 \% \mathrm{CI}: 0.32,1.69)$. For each unit increase of age, there was 0.02 increase in AMR attitude scores ( $\beta=0.02 ; 95 \%$ CI: $0.01,0.04)$. The scores were significantly associated with the participant's level of education; compared to participants who had not attained formal education, participants with college/university $(\beta=2.43 ; 95 \%$ CI: $1.13,3.74)$, secondary $(\beta=1.76 ; 95 \%$ CI: $0.95,2.58)$ and primary ( $\beta=1.42$; $95 \%$ CI: $0.75,2.09)$ had higher scores. Being employed was associated with low AMR attitude scores ( $\beta=-1.30 ; 95 \% \mathrm{CI}:-2.15,-0.45$ ) while a marginal association was observed between the scores and petty trading ( $\beta=0.54 ; 95 \%$ CI: $0.01,1.08$ ). The practices on AMU was significantly associated with an increase in participant's age $(\beta=0.01 ; 95 \% \mathrm{CI}$ : 0.001 , $0.009)$. Being employed was significantly associated with low practice scores ( $\beta=-0.22$; 95\% CI: $-0.43,-0.01$ ).

Multiple linear regression analysis showed that residing in Ilala $\left(\beta_{\text {adj }}=-0.82\right.$; 95\% CI: $\left.-1.24,-0.40\right)$ and Kilosa ( $\beta_{\text {adj }}$ $=-0.42 ; 95 \%$ CI: $-0.81,-0.03)$, and being married, $\left(\beta_{\text {adj }}\right.$ $=0-0.3 ; 95 \%$ CI: $-0.62,-0.02)$ were significantly associated with low scores of knowledge. On the contrary, increase in the level of education (university/college, $\beta_{\text {adj }}=2.48$; $95 \%$ CI: $1.70,3.25$, secondary, $\beta_{\text {adj }}=1.49$; $95 \%$ CI: 0.95 , 2.03 , primary, $\beta_{\text {adj }}=1.07 ; 95 \%$ CI: $\left.0.66,1.49\right)$ was significantly associated with increased AMU knowledge scores. The factors that were associated with high scores of AMR knowledge were old age ( $\beta_{\text {adj }}=0.04,95 \%$ CI: $\left.0.02,0.07\right)$, being a male $\left(\beta_{\mathrm{adj}}=0.09 ; 95 \%\right.$ CI: $\left.0.12,1.65\right)$ and having attained college/university $\left(\beta_{\text {adj }}=3.28 ; 95 \% \mathrm{CI}\right.$ : $\left.1.39,5.17\right)$ and secondary ( $\beta_{\text {adj }}=1.56 ; 95 \%$ CI: $\left.0.25,2.87\right)$ education. Compared with participants from Kibaha, significantly higher scores of AMU attitudes were recorded among participants from Ilala ( $\beta_{\text {adj }}=1.91 ; 95 \%$ CI: $\left.0.98,2.85\right)$ and Kilosa ( $\beta_{\text {adj }}=1.56$; 95\% CI: 0.70, 2.43). College/university $\left(\beta_{\text {adj }}=1.89 ; 95 \%\right.$ CI: $\left.0.18,3.60\right)$ and primary $\left(\beta_{\text {adj }}=1.87\right.$; $95 \%$ CI: $0.95,2.79)$ levels of education were significantly associated with AMU attitude score gain. Each unit increase in the participant's age had a significant influence on AMR attitude scores $\left(\beta_{\mathrm{adj}}=0.04 ; 95 \% \mathrm{CI}\right.$ : $0.02,0.06)$. Having attained college/university $\left(\beta_{\mathrm{adj}}=2.21\right.$; 95\% CI: 0.82, 3.61), secondary $\left(\beta_{\mathrm{adj}}=2.00\right.$; 95\% CI: 1.02 , $2.97)$, or primary $\left(\beta_{\mathrm{adj}}=1.49 ; 95 \% \mathrm{CI}: 0.74,2.24\right)$ education was significantly associated with increased AMR attitude scores. The AMU practice score gains was influenced by participant's level of education; compared to those who had not attained formal education, those with college/university $\left(\beta_{\mathrm{adj}}=0.35 ; 95 \%\right.$ CI: $\left.0.07,0.63\right)$, secondary $\left(\beta_{\mathrm{adj}}=0.24 ; 95 \% \mathrm{CI}: 0.05,0.44\right)$, or primary $\left(\beta_{\mathrm{adj}}=0.19\right.$; $95 \%$ CI: 0.04, 0.34) education had higher scores. The overall increase in KAP scores were significantly influenced by increased participant's age $\left(\beta_{\text {adj }}=0.10 ; 95 \%\right.$ CI: $0.05,0.15)$ and increased level of education; primary $\left(\beta_{\mathrm{adj}}=5.32 ; 95 \% \mathrm{CI}\right.$ : 3.27, 7.37), secondary $\left(\beta_{\mathrm{adj}}=6.18\right.$; $95 \%$ CI: $3.53,8.84)$ and college/university $\left(\beta_{\mathrm{adj}}=9.85 ; 95 \% \mathrm{CI}\right.$ : $6.04,13.67)$.

The greatest positive correlations of the variables were observed between AMU knowledge scores and AMU practice scores ( rho $=0.201$ ); AMR knowledge scores and AMU attitude scores (rho $=0.271$ ); AMU attitude scores and AMR attitude scores (rho $=0.280$ ); and AMR knowledge scores and AMR attitude score (rho $=0.392$ ). The greatest negative correlation was observed between age and education level (rho $=-0.316$ ) (Fig. 9).

\section{Association between KAP scores}

The results of linear regression analysis of the association between KAP scores showed that each unit increase in AMU knowledge score was associated with 0.06 increase in the AMU practice scores $(\beta=0.06$; $95 \%$ CI: $0.04,0.09)$. For each unit increase of AMR knowledge score, there was 0.21 increase in the scores of AMR attitude $(\beta=0.21$; $95 \%$ CI: 0.16, 0.25). Each unit increase on AMU attitude scores was associated with a 0.01 increase in the AMU practice scores $(\beta=0.01 ; 95 \%$ CI: $0.01,0.02)$. The results showed further that AMU knowledge scores $\left(\beta_{\mathrm{adj}}=0.06\right.$; $95 \%$ CI: $0.03,0.08)$ and AMU attitude scores $\left(\beta_{\mathrm{adj}}=0.01\right.$; $95 \%$ CI: $0.01,0.03$ ) together had a better influence on the increase in $\mathrm{AMU}$ practice scores than their independent effect.

\section{Discussion}

Inappropriate AMU and associated risk of AMR is an increasing public health problem globally [37] with potentially devastating consequences in $\operatorname{LMIC}_{S}[22,23]$. The results of this study suggest that there is a high level of awareness regarding antimicrobials and their use for disease management in humans in the three districts selected for this study. However, there is insufficient knowledge about AMU and AMR. The level of awareness observed in our study regarding antimicrobials and their use is similar to the findings reported by studies 


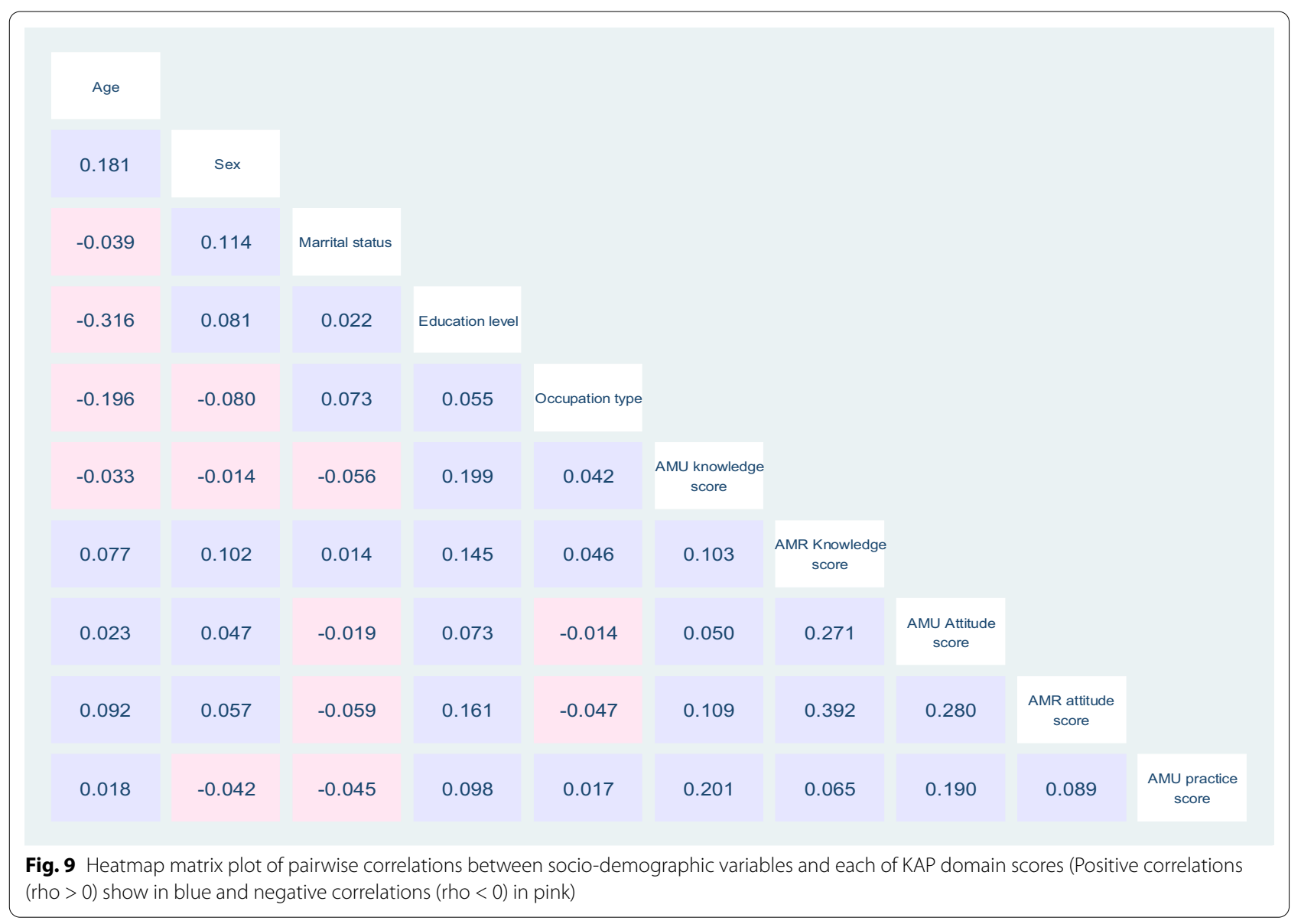

in Nepal and Jordan [38, 39]. The observed poor knowledge regarding AMU and AMR accords with the findings reported previously $[39,40]$. The pattern observed in our study for knowledge of AMU and AMR to increase with an increased level of participants' education, contrasts with the findings of previous studies elsewhere [39-42]. Overall, over half of the participants were not aware of AMR and the knowledge level was considered moderate, similar to the finding reported in Nepal [39]. However, the level observed in our study is lower than that reported in Norway [43]. From the literature, quite a few studies have explored the knowledge of the general population on AMR. Most have focused on specific groups of individuals such as professionals and students [42, 4446]. A recent systematic review [47] has indicated that only a small proportion of participants in Europe (43\%), Asia (26\%) and North America (22\%) have ever heard of AMR.

We found that AMU was a common practice and amoxicillin was the most preferred antimicrobial. The findings correspond to those reported in Ethiopia [41], Uganda [48], and Asia [39]. Based on the fact that that increased frequency of $A M U$ is a significant driver of
AMR, especially when they are used inappropriately [49-51], it is plausible to suggest that these most used antimicrobials are at increased risk of resistance. For instance, amoxicillin use has been strongly associated with increased carriage of amoxicillin-resistant bacteria [52] and high multidrug resistance has been reported in a recent systematic review [51]. Given the low rate of development of new generations of antimicrobials, rational use of existing ones is critical for the long-term availability of effective treatment of infections [42, 43]. The pathogen-specific epidemiological models of AMR have been proposed for community-acquired infections [53] and the volume of drug use has been identified as the major selection pressure driving changes in the frequency of AMR in the community [54].

The frequent sources of antimicrobials reported were the healthcare facility and pharmacies/basic drugs shop, which is similar to the findings reported elsewhere [10, $39,55]$. Retail pharmacies have emerged as the primary level of outpatient care in Africa leading to use of antimicrobials without consultation, confirmatory diagnosis or prescription [16, 17]. Pharmacies [55] and healthcare facilities [56,57] have been reported as the most common 
sources of antimicrobials associated with increased use in the community. In most low- and middle-income countries (LMIC), antimicrobials can be obtained from such sources without medical prescriptions [14]. Previous studies in Tanzania reported a high rate of non-prescription dispensing of antimicrobials from the pharmacies $[55,58]$. It has been suggested elsewhere that physicians may attempt to meet a patient's expectation even though they feel antimicrobials are unnecessary [59]. The health care facilities in most of LMIC are characterized with inadequate laboratory diagnostic capacity and the high clinician-patient ratio $[60,61]$. There is often no evidence-based decision in the course of treatment, and the clinicians are overwhelmed and there is frequently an inadequate time for sufficient education and communication with the patient on adherence to the treatment regimen and its importance [23]. It seems that the practice of obtaining antimicrobials from pharmacies/basic drugs shops without prescription or by the participant's pressure to influence prescription together with low knowledge may elevate inappropriate use of antimicrobials leading to the potential risk for AMR. Pharmacies appear to be more accessible to the public as they are characterized by shorter waiting time, free consultation and negotiations on treatment options based on the financial capability of the patients [16].

In our study, we recorded a moderate attitude regarding the appropriate use of antimicrobial, which was a lower level than previously reported by other studies in Tanzania [40] and in Hong Kong [62]. However, the different scoring schemes used between our study and these other studies might have led to the different conclusions made regarding the attitude scores. For instance, whereas in our study the observed score of $72.7 \%$ was considered moderate, the study by Mbwambo and others [40] reported a score of $62.7 \%$ that was regarded as good knowledge of antimicrobials use. A study in Hong Kong [62] found the level of $77.0 \%$ that was considered an adequate knowledge of antimicrobial use. Individual's attitude has been reported to influence antimicrobial use practices [63-66]. The observed level of knowledge and attitude may have influenced the AMU practice documented in the study districts as it has been suggested elsewhere [40, 67, 68]. Being of old age and with an increased level of education were found to influence KAP scores, the observation which contrasts with other studies [40, 42, 69]. In our study, the practices of self-medication were more frequent among men than women. Studies elsewhere have also reported that selfmedication with antimicrobials is associated with male gender [70]. The prevalence of self-medication in this study was $23.6 \%$, which is lower than that reported previously in Tanzania $[55,71]$. In a recent systematic review, a prevalence of $7.3 \%$ to $85.6 \%$ self-medication of antimicrobial was reported in South-East Asia countries [72]. Selfmedication with antimicrobial has been described as one of the major factors contributing to drug resistance [51, 73]. The problem of self-medication is a common practice in LMIC including Tanzania. Results from previous studies in Kilosa and Moshi districts in Tanzania showed that the guardians/parents practice self-medication and once their children get sick, they preferred to purchase drugs from the pharmacies /drug shops or use left-over medicines from their homes, neighbours, relatives or friends and other sought advice from vendors [74, 75].

The observed inadequate knowledge of AMU and AMR, inappropriate attitude and practices should be considered as alarming problems and potential signals for the occurrence of AMR that require immediate action. Policy and decision-makers could make use of the evidence generated by this study as one of the inputs to reinforce the medicine use policy and guidelines to mitigate the risk of AMR. Our findings call for tailored interventions such as education programmes targeting the community regarding appropriate use antimicrobial and appropriate ways to prevent AMR. Specific groups should be targeted for education programmes, such as those with a lower level of formal education, who have demonstrated less knowledge and inappropriate attitudes and poor practices to antimicrobial use and measures against their resistance.

\section{Limitations}

When interpreting the findings from this study, it is important to note some of its limitations. First, the selection of a limited number of study regions, districts and wards was based largely on a purposive selection process. This means that it will be difficult to draw generalizable inferences from the results obtained in the few areas. However, the findings could apply to areas with similar settings. Second, the quality of some of the interviewbased data might have been affected by recall bias and decision to share desirable and undesirable practices amongst the participants. Third, the role of other potentially relevant explanatory factors was not ruled out in our analysis. For instance, household structure (including family size and age distribution) and economic (wealth) status were not considered in this study. Sociodemographic variables were limited to only the respondent who represented the household. Inclusion of other potential parameters might have improved further our understanding regarding AMU and AMR in the study areas. Fourth, because of the cross-sectional nature of the study, it was not possible to establish causal inferences between knowledge, attitudes and practices. Besides its limitations, this study provides important information 
for targeted mitigation measures to address challenges related to the inappropriate use of antimicrobials and AMR in the study areas. The generated data could save as baseline or reference for future research and monitor the efficiency of future interventions.

\section{Conclusion}

This study has provided information on the levels of knowledge of AMU and AMR, sources, attitudes and AMU practices in Ilala, Kibaha and Kilosa districts. The study documented a moderate level of knowledge, attitudes and practices regarding AMU and AMR in the districts. The results suggest that old age and high level of education together had a positive influence on the knowledge, attitudes and practices regarding AMU and AMR. The correlation between knowledge and attitudes was moderate; and poor between knowledge and practices; and attitudes and practices. The findings are important to guide policy formulation, planning and implementation of AMU and AMR related programmes, especially those targeting community-based awareness, education and sensitization.

\section{Abbreviations}

AMU: Antimicrobial use; AMR: Antimicrobial resistance; KAP: Knowledge, attitudes and practices; LMICS: Low and middle-income countries; IQR: Interquartile range; $\beta$ : Regression coefficient beta; $\beta$ adj: Adjusted coefficient beta; $95 \% \mathrm{Cl}$ : 95 percent confidence intervals; \%: Percentage; rho: Spearman rank-order correlation coefficient.

\section{Acknowledgements}

We would like to thank all the study participants whose understanding and cooperation made this study a success. We extend our thanks to the regional and district authorities including the respective Regional Administrative Secretary, District Executive Directors, District Medical and Veterinary Officers and District Project Focal persons for their support and facilitation of the study implementation. Our special thanks go to the ward leaders for facilitation and community engagement in their respective areas. We acknowledge the support received from our research assistants during the course of data collection. They were Isolide Massawe, David Kiwera, Fausta Mgaya, Fortunata Nyeringo, Gilbert Mwageni, Jackson Kisamo, Jesca Michael, John Ng'imba, Joyce Kasuamila, Magao Mhando, Pendo Mtui and Shoko Kashenge.

\section{Authors' contributions \\ Conceptualization: MM, LEGM, GF, CS, BKZ, SEM, SK and MMR. Methodology and investigation: MM, LEGM, GF, CS, BKZ, and SK. Supervision of data collec- tion: CS and BKZ. Data curation and formal analysis: CS. Writing-original draft preparation: CS. Writing-review, editing, visualization and interpretation of data: CS, MM, LEGM, GF, BKZ, SM, SK, TGC and HL. Project administration and funding acquisition: MM. All authors approved the submitted version of the manuscript.}

\section{Funding}

This study received financial support from the Medical Research Council of the United Kingdom.

\section{Availability of data and materials}

The datasets generated and/or analysed during the current study are available in the Muhumbili University of Health and Allied Sciences (MUHAS) in Dar es Salaam, Tanzania and is available on reasonable request.

\section{Ethics approval and consent to participate}

The Medical Research Coordinating Committee of the Tanzania National Institute for Medical Research approved the protocol (Ref No. NIMR/HQ/R.8a/Vol IX/3147). All study participants provided their informed consent for inclusion before they participated in the study.

\section{Consent for publication}

Not applicable.

\section{Competing interests}

The authors declare that they have no competing interests.

\section{Author details}

${ }^{1}$ National Institute for Medical Research, Tabora Research Centre, Tabora, Tanzania. ${ }^{2}$ SACIDS Foundation for One Health, Sokoine University of Agriculture, Morogoro, Tanzania. ${ }^{3}$ Tanzania Commission for Science and Technology, Dar es Salaam, Tanzania. ${ }^{4}$ Muhimbili University of Health and Allied Sciences, Dar es Salaam, Tanzania. ${ }^{5}$ College of Veterinary Medicine and Biomedical Sciences, Sokoine University of Agriculture, Morogoro, Tanzania. ${ }^{6}$ London School of Hygiene and Tropical Medicine, London, United Kingdom. ${ }^{7}$ Catholic University of Health and Allied Sciences, Mwanza, Tanzania.

Received: 21 September 2020 Accepted: 22 November 2020

Published online: 07 December 2020

\section{References}

1. Byarugaba DK. Antimicrobial resistance in developing countries and responsible risk factors. Int J Antimicrob Agents. 2004;24:105-10.

2. Kajeguka D, Moses EA. Self-medication practices and predictors for self-medication with antimicrobials and antimalarials among community in Mbeya City, Tanzania. Tanzania J Health Res. 2017;19(4). https://doi. org/10.4314/thrb.v19i4.

3. Okeke IN, Laxminarayan R, Bhutta ZA, Duse AG, Jenkins P, O'Brien TF, et al. Antimicrobial resistance in developing countries. Part I: recent trends and current status. Lancet Infect Dis. 2005;5:481-93.

4. Radyowijati A, Haak H. Improving antibiotic use in low-income countries: an overview of evidence on determinants. Soc Sci Med. 2003;57:733-44.

5. Mshana SE, Matee M, Rweyemamu M. Antimicrobial resistance in human and animal pathogens in Zambia, Democratic Republic of Congo, Mozambique and Tanzania: an urgent need of a sustainable surveillance system. Ann Clin Microbiol Antimicrob. 2013;12:28.

6. Moremi N, Manda EV, Falgenhauer L, Ghosh H, Imirzalioglu C, Matee M, et al. Predominance of CTX-M-15 among ESBL Producers from Environment and Fish Gut from the Shores of Lake Victoria in Mwanza, Tanzania. Front Microbiol. 2016;7 [cited 2020 Jul 4]. Available from: http://journ al.frontiersin.org/article/10.3389/fmicb.2016.01862/full.

7. Moyo SJ, Aboud S, Blomberg B, Mkopi N, Kasubi M, Manji K, et al. High Nasal Carriage of Methicillin-Resistant Staphylococcus aureus Among Healthy Tanzanian Under-5 Children. Microb Drug Resist. 2014;20:82-8.

8. Manyahi J, Matee MI, Majigo M, Moyo S, Mshana SE, Lyamuya EF. Predominance of multi-drug resistant bacterial pathogens causing surgical site infections in Muhimbili national hospital, Tanzania. BMC Res Notes. 2014;7:500.

9. Michael CA, Dominey-Howes D, Labbate M. The antimicrobial resistance crisis: causes, consequences, and management. Front Public Health. 2014;2 [cited 2020 Jul 5]. Available from: http://journal.frontiersin.org/ article/10.3389/fpubh.2014.00145/abstract.

10. Simba D, Kakoko D, Semali I, Kessy A, Embrey M. Household knowledge of antimicrobials and antimicrobial resistance in the wake of an accredited drug dispensing outlet (ADDO) program rollout in Tanzania. Butaye $\mathrm{P}$, editor. PLoS One. 2016;11:e0163246.

11. Thriemer K, Katuala Y, Batoko B, Alworonga J-P, Devlieger H, Van Geet $C$, et al. Antibiotic Prescribing in DR Congo: A Knowledge, Attitude and Practice Survey among Medical Doctors and Students. Meng X, editor. PLoS One. 2013;8:e55495.

12. Pulcini C, Williams F, Molinari N, Davey P, Nathwani D. Junior doctors' knowledge and perceptions of antibiotic resistance and prescribing: a survey in France and Scotland. Clin Microbiol Infect. 2011;17:80-7. 
13. Okeke IN, Klugman KP, Bhutta ZA, Duse AG, Jenkins P, O'Brien TF, et al. Antimicrobial resistance in developing countries. Part II: strategies for containment. Lancet Infect Dis. 2005;5:568-80.

14. Lansang MA, Lucas-Aquino R, Tupasi TE, Mina VS, Salazar LS, Juban N, et al. Purchase of antibiotics without prescription in Manila, The Philippines. Inappropriate choices and doses. J Clin Epidemiol. 1990;43:61-7.

15. Kunin CM. Resistance to Antimicrobial Drugs-A Worldwide Calamity. Ann Intern Med. 1993;118:557.

16. Goel P, Ross-Degnan D, Berman P, Soumerai S. Retail pharmacies in developing countries: a behavior and intervention framework. Soc Sci Med. 1996:42:1155-61.

17. Kwena Z, Sharma A, Wamae N, Muga C, Bukusi E. Provider Characteristics Among Staff Providing Care to Sexually Transmitted Infection Self-Medicating Patients in Retail Pharmacies in Kibera Slum, Nairobi, Kenya. Sex Transm Dis. 2008;35:480-3.

18. Basco LK. Molecular epidemiology of Malaria in Cameroon. XIX. Quality of antimalarial drugs used for self-medication. Am J Trop Med Hyg. 2004;70:245-50

19. Bebell LM, Muiru AN. Antibiotic Use and Emerging Resistance: How Can Resource-Limited Countries Turn the Tide? Glob Heart. 2014;9:347.

20. Cockburn R, Newton PN, Agyarko EK, Akunyili D, White NJ. The global threat of counterfeit drugs: why industry and governments must communicate the dangers. PLoS Med. 2005;2:e100.

21. Katakweba AAS, Mtambo MMA, Olsen JE, Muhairwa AP. Awareness of human health risks associated with the use of antimicrobials among livestock keepers and factors that contribute to selection of antimicrobial resistance bacteria within livestock in Tanzania. Livestock Res Rural Dev. 2012;24(10).

22. Okeke IN, Aboderin OA, Byarugaba DK, Ojo KK, Opintan JA. Growing Problem of Multidrug-Resistant Enteric Pathogens in Africa. Emerg Infect Dis. 2007;13:1640-6.

23. Ayukekbong JA, Ntemgwa M, Atabe AN. The threat of antimicrobial resistance in developing countries: causes and control strategies. Antimicrob Resist Infect Control. 2017;6:47.

24. IACG. Surveillance and monitoring for antimicrobial use and resistance. Interag Coord Group Antimicrob Resist. 2018; [cited 2020 Aug 17]. Available from: https://www.who.int/antimicrobial-resistance/interagenc y-coordination-group/IACG_Surveillance_and_Monitoring_for_AMU_ and_AMR_110618.pdf?ua=1.

25. Yevutsey SK, Buabeng KO, Aikins M, Anto BP, Biritwum RB, Frimodt-Møller $\mathrm{N}$, et al. Situational analysis of antibiotic use and resistance in Ghana: policy and regulation. BMC Public Health. 2017;17:896.

26. Pulcini C, Gyssens IC. How to educate prescribers in antimicrobial stewardship practices. Virulence. 2013;4:192-202.

27. Karimuribo E, Mdegela R, Kusiluka L, Kambarage D. Assessment of drug usage and antimicrobial residues in milk on smallholder farms in Morogoro, TanzaniaEvaluation de l'utilisation des medicaments et determination des residus antimicrobiens dans le lait dans les petites exploitations agricoles a Morogoro en Tanzanie. Bull Anim Health Prod Afr. 2006;53:234-41

28. Mmbando LMG. Investigation of oxytetracyclineuse and abuse: Determination of its residue inmeat consumed in Dodoma and Morogoro [A thesissubmitted for the award of a MVM Degree at Sokoine University of Agriculture, Morogoro, Tanzania]; 2004

29. Parsonage B, Hagglund PK, Keogh L, Wheelhouse N, Brown RE, Dancer SJ. Control of antimicrobial resistance requires an ethical approach. Front Microbiol. 2017:8:2124.

30. Karimuribo ED, Mutagahywa E, Sindato C, Mboera L, Mwabukusi M, Kariuki Njenga M, et al. A Smartphone App (AfyaData) for Innovative One Health Disease Surveillance from Community to National Levels in Africa: Intervention in Disease Surveillance. JMIR Public Health Surveill. 2017;3:e94.

31. Monjeza GL. People's knowledge, attitude and practices about self medication and its implications in Ilala Municipality, Dar es Salaam [MPH Dissertation]. Dar es Salaam, Tanzania: Muhimbili University of Health and Allied Sciences; 2013.

32. Hounmanou YMG, Mdegela RH. Current situation for antimicrobial use, antimicrobial resistance and antimicrobial residues in the food and agriculture sectors in Tanzania: A review. Special Issue TVA Proceedings, Tanzania Vet J. 2017;35.
33. Caudell MA, Quinlan MB, Subbiah M, Call DR, Roulette CJ, Roulette JW, et al. Antimicrobial Use and Veterinary Care among Agro-Pastoralists in Northern Tanzania. Browning GF, editor. PLoS One. 2017;12:e0170328.

34. Shah P, Shrestha R, Mao Z, Chen Y, Chen Y, Koju P, et al. Knowledge, attitude, and practice associated with antibiotic use among University students: a survey in Nepal. Int J Environ Res Public Health. 2019;16:3996.

35. Sawalha AF. A descriptive study of self-medication practices among Palestinian medical and nonmedical university students. Res Soc Adm Pharm. 2008:4:164-72.

36. Chen X, Ender PB, Mitchell M, Wells C. Logistic regression diagnosis. Academic Technology Services, Statistical Consulting Group: UCLA; 2010.

37. Prestinaci F, Pezzotti P, Pantosti A. Antimicrobial resistance: a global multifaceted phenomenon. Pathog Glob Health. 2015;109:309-18.

38. Shehadeh M, Suaifan G, Darwish RM, Wazaify M, Zaru L, Alja'fari S. Knowledge, attitudes and behavior regarding antibiotics use and misuse among adults in the community of Jordan. A pilot study. Saudi Pharm J. 2012;20:125-33.

39. Nepal A, Hendrie D, Robinson S, Selvey LA. Knowledge, attitudes and practices relating to antibiotic use among community members of the Rupandehi District in Nepal. BMC Public Health. 2019;19:1558.

40. Goodluck M, Basiliana E, Maseke RM, Geofrey NS, Debora CK. Community knowledge and attitudes on antibiotic use in Moshi Urban, Northern Tanzania: Findings from a cross sectional study. Afr J Microbiol Res. 2017;11:1018-26.

41. Gebeyehu E, Bantie L, Azage M. Inappropriate Use of Antibiotics and Its Associated Factors among Urban and Rural Communities of Bahir Dar City Administration, Northwest Ethiopia. Ciccozzi M, editor. PLoS One. 2015;10:e0138179.

42. Azevedo MM, Pinheiro C, Yaphe J, Baltazar F. Portuguese students' knowledge of antibiotics: a cross-sectional study of secondary school and university students in Braga. BMC Public Health. 2009:9:359.

43. Waaseth M, Adan A, Røen IL, Eriksen K, Stanojevic T, Halvorsen KH, et al. Knowledge of antibiotics and antibiotic resistance among Norwegian pharmacy customers - a cross-sectional study. BMC Public Health. 2019;19:66.

44. Jamshed SQ, Elkalmi R, Rajiah K, Al-Shami AK, Shamsudin SH, Siddiqui MJA, et al. Understanding of antibiotic use and resistance among finalyear pharmacy and medical students: a pilot study. J Infect Dev Ctries. 2014;8:780-5.

45. Seid MA, Hussen MS. Knowledge and attitude towards antimicrobial resistance among final year undergraduate paramedical students at University of Gondar, Ethiopia. BMC Infect Dis. 2018;18:312.

46. Nisabwe L, Brice H, Umuhire MC, Gwira O, Harelimana JDD, Nzeyimana $Z$, et al. Knowledge and attitudes towards antibiotic use and resistance among undergraduate healthcare students at University of Rwanda. J Pharm Policy Pract. 2020;13:7.

47. McCullough AR, Parekh S, Rathbone J, Del Mar CB, Hoffmann TC. A systematic review of the public's knowledge and beliefs about antibiotic resistance. J Antimicrob Chemother. 2016;71:27-33.

48. Ocan M, Bwanga F, Bbosa GS, Bagenda D, Waako P, Ogwal-Okeng J, et al. Patterns and predictors of self-medication in northern Uganda. PloS One. 2014;9:e92323.

49. Bell BG, Schellevis F, Stobberingh E, Goossens H, Pringle M. A systematic review and meta-analysis of the effects of antibiotic consumption on antibiotic resistance. BMC Infect Dis. 2014;14:13.

50. Chung A, Perera R, Brueggemann AB, Elamin AE, Harnden A, MayonWhite $R$, et al. Effect of antibiotic prescribing on antibiotic resistance in individual children in primary care: prospective cohort study. BMJ. 2007;335:429.

51. Muhie OA. Antibiotic Use and Resistance Pattern in Ethiopia: Systematic Review and Meta-Analysis. Int J Microbiol. 2019;2019:2489063.

52. Malhotra-Kumar S, Van Heirstraeten L, Coenen S, Lammens C, Adriaenssens $N$, Kowalczyk A, et al. Impact of amoxicillin therapy on resistance selection in patients with community-acquired lower respiratory tract infections: a randomized, placebo-controlled study. J Antimicrob Chemother. 2016;71:3258-67.

53. Austin DJ, Kakehashi M, Anderson RM. The transmission dynamics of antibiotic-resistant bacteria: the relationship between resistance in commensal organisms and antibiotic consumption. Proc R Soc Lond B Biol Sci. 1997;264:1629-38. 
54. Austin DJ, Kristinsson KG, Anderson RM. The relationship between the volume of antimicrobial consumption in human communities and the frequency of resistance. Proc Natl Acad Sci. 1999;96:1152-6.

55. Horumpende PG, Said SH, Mazuguni FS, Antony ML, Kumburu HH, Sonda $\mathrm{TB}$, et al. Prevalence, determinants and knowledge of antibacterial selfmedication: A cross sectional study in North-eastern Tanzania. Singer AC, editor. PLoS One. 2018;13:e0206623.

56. Desalegn AA. Assessment of drug use pattern using WHO prescribing indicators at Hawassa University Teaching and Referral Hospital, south Ethiopia: a cross-sectional study. BMC Health Serv Res. 2013;13:170.

57. Fenta A, Belay M, Mekonnen E. Assessment of antibacterial drug exposure patterns of patient encounters seen by different categories of prescribers at health institutions in Bahir Dar, Ethiopia. Ethiop Med J. 2013;51:33-9.

58. Kagashe GAB, Minzi O, Matowe L. An assessment of dispensing practices in private pharmacies in Dar-es-Salaam, Tanzania. Int J Pharm Pract. 2011;19:30-5.

59. Butler CC, Rollnick S, Pill R, Maggs-Rapport F, Stott N. Understanding the culture of prescribing: qualitative study of general practitioners' and patients' perceptions of antibiotics for sore throats. BMJ. 1998;317:637-42.

60. Alemnji GA, Zeh C, Yao K, Fonjungo PN. Strengthening national health laboratories in sub-Saharan Africa: a decade of remarkable progress. Trop Med Int Health. 2014;19:450-8.

61. Mboera LEG, Ipuge Y, Kumalija CJ, Rubona J, Perera S, Masanja H, et al. Midterm review of national health plans: an example from the United Republic of Tanzania. Bull World Health Organ. 2015;93:271-8.

62. You JHS, Yau B, Choi KC, Chau CTS, Huang QR, Lee SS. Public Knowledge Attitudes and Behavior on Antibiotic Use: A Telephone Survey in Hong Kong. Infection. 2008;36:153-7.

63. Togoobaatar G, Ikeda N, Ali M, Sonomjamts M, Dashdemberel S, Mori R, et al. Survey of non-prescribed use of antibiotics for children in an urban community in Mongolia. Bull World Health Organ. 2010;88:930-6.

64. Belongia EA, Naimi TS, Gale CM, Besser RE. Antibiotic use and upper respiratory infections: a survey of knowledge, attitudes, and experience in Wisconsin and Minnesota. Prev Med. 2002;34:346-52.

65. Mangione-Smith R, McGlynn EA, Elliott MN, McDonald L, Franz CE, Kravitz RL. Parent expectations for antibiotics, physician-parent communication, and satisfaction. Arch Pediatr Adolesc Med. 2001;155:800.

66. Finch RG, Metlay JP, Davey PG, Baker LJ. Educational interventions to improve antibiotic use in the community: report from the International
Forum on Antibiotic Resistance (IFAR) colloquium, 2002. Lancet Infect Dis. 2004;4:44-53.

67. Awad Al, Aboud EA. Knowledge, attitude and practice towards antibiotic use among the public in Kuwait. Singer AC, editor. PLoS One. 2015;10:e0117910.

68. Kim SS, Moon S, Kim EJ. Public Knowledge and Attitudes Regarding Antibiotic Use in South Korea. J Korean Acad Nurs. 2011;41:742.

69. Andreas R, Vassiliki P, Adamos H, Sotiria P, Maria T, George S, Christos H. Descriptive study on parents' knowledge, attitudes and practices on antibiotic use and misuse in children with upper respiratory tract infections in cyprus. Int J Environ Res Public Health. 2011;8:3246-62. https://doi. org/10.3390/ijerph8083246.

70. Ateshim Y, Bereket B, Major F, Emun Y, Woldai B, Pasha I, et al. Prevalence of self-medication with antibiotics and associated factors in the community of Asmara, Eritrea: a descriptive cross sectional survey. BMC Public Health. 2019;19:726.

71. Esuvat-Moses A, Mgabo MR, Mwabamba G, Mrema JG, Kajeguka DC. Prevalence and knowledge of self-medication: a cross sectional study in Mbeya Urban. Southwestern Tanzania. 2017;2(1):1014.

72. Nepal G, Bhatta S. Self-medication with Antibiotics in WHO Southeast Asian Region: a systematic review. Cureus. 2018; [cited 2020 Jul 4]; Available from: https://www.cureus.com/articles/11580-self-medication -with-antibiotics-in-who-southeast-asian-region-a-systematic-review.

73. Rather IA, Kim B-C, Bajpai VK, Park Y-H. Self-medication and antibiotic resistance: Crisis, current challenges, and prevention. Saudi J Biol Sci. 2017;24:808-12.

74. Chipwaza B, Mugasa JP, Mayumana I, Amuri M, Makungu C, Gwakisa PS. Self-medication with anti-malarials is a common practice in rural communities of Kilosa district in Tanzania despite the reported decline of malaria. Malar J. 2014;13:252.

75. Lyimo B, Buza J, Subbiah M, Smith W, Call DR. Comparison of antibiotic resistant Escherichia coli obtained from drinking water sources in northern Tanzania: a cross-sectional study. BMC Microbiol. 2016;16:254.

\section{Publisher's Note}

Springer Nature remains neutral with regard to jurisdictional claims in published maps and institutional affiliations.
Ready to submit your research? Choose BMC and benefit from:

- fast, convenient online submission

- thorough peer review by experienced researchers in your field

- rapid publication on acceptance

- support for research data, including large and complex data types

- gold Open Access which fosters wider collaboration and increased citations

- maximum visibility for your research: over 100M website views per year

At BMC, research is always in progress.

Learn more biomedcentral.com/submissions 